\title{
C-Reactive Protein Gene Variants in Depressive Symptoms \& Antidepressants Efficacy
}

\author{
Xinxin $\mathrm{Li}^{1,2}$, Ning Sun ${ }^{1}$, Chunxia Yang ${ }^{1}$, Zhifen Liu ${ }^{1}$, Xinrong Li ${ }^{1}$, and Kerang Zhang ${ }^{1 凶}$ \\ ${ }^{1}$ Department of Psychiatry, First Hospital of Shanxi Medical University, Taiyuan, China \\ ${ }^{2}$ Shanxi Medical University, Taiyuan, China
}

\begin{abstract}
Objective Although the pathogenesis of depression remains unclear, C-reactive protein (CRP) levels are commonly elevated in depressed patients. Thus, CRP single-nucleotide polymorphisms (SNPs) that influence CRP levels may be associated with depression. In the present study, we explored whether CRP SNPs are related to depressive symptoms and antidepressants efficacy in Han Chinese patients.

Methods We analyzed data from 440 patients with first-episode depression. We obtained genome CRP SNPs, scores of the 17-item Hamilton Rating Scale for Depression 17 (HAMD17) and its four-factor at baseline and after 6 weeks. Quantitative trait analysis was performed using UNPHASED software and curative effects were analyzed using SPSS software.

Results Male patients with SNP rs1800947G exhibited lower insomnia scores and rs2794521CC exhibited lower scores of anxiety/ physical symptoms, total HAMD17 score. Female patients with rs2794521TT exhibited higher scores of insomnia and lower antidepressants efficacy.

Conclusion CRP SNPs rs1800947 and rs2794521 may be associated with depressive symptoms in patients with depression in a sex-specific fashion. Furthermore, rs2794521 may be a predictor of the efficacy of antidepressants in female patients.
\end{abstract}

Psychiatry Investig 2019;16(12):940-947

Key Words Depression, Single-nucleotide polymorphism, Antidepressant, C-reactive protein, 6-week follow-up.

\section{INTRODUCTION}

Depression, the most common mood disorder, is associated with high rates of morbidity, mortality, and disability. Only a small proportion of patients are cured of their depression. Therefore, there is a critical need to develop effective therapeutic strategies and individualized treatment options. ${ }^{1}$

Both animal and human studies have revealed that various mood disorders (including depression) induce inflammatory responses, including changes in levels of inflammatory markers and in their responses to psychiatric treatments. ${ }^{2-5}$ Such studies have reported that $\mathrm{C}$-reactive protein (CRP) levels in the cerebrospinal fluid (CSF) are elevated in patients with de-

\footnotetext{
Received: May 9, 2019 Revised: July 3, 2019

Accepted: September 5, 2019

$\bowtie$ Correspondence: Kerang Zhang, MD, PhD

Department of Psychiatry, First Hospital of Shanxi Medical University, Taiyuan 030001, People's Republic of China

Tel: +86-351-4639869, Fax: +86-351-4639956, E-mail: atomsxmu@vip.163.com

(c) This is an Open Access article distributed under the terms of the Creative Commons Attribution Non-Commercial License (https://creativecommons.org/licenses/by$\mathrm{nc} / 4.0$ ) which permits unrestricted non-commercial use, distribution, and reproduction in any medium, provided the original work is properly cited.
}

pression. ${ }^{6}$ Thus, CRP concentration may be a marker for central and peripheral inflammation, suggesting that CRP plays an important role in the pathogenesis of depression. ${ }^{7-11}$

Although accumulating evidence has demonstrated that depressive symptoms and antidepressants efficacy are positively associated with circulating CRP levels, the results of previous studies have been inconsistent. ${ }^{12-17}$ Differences in comorbidities, lifestyle factors, and socioeconomic status may explain these discrepancies. ${ }^{18}$ Genetic studies may help to clarify these relationships, since the genetic effects are not influenced by such confounding factors. Four CRP single-nucleotide polymorphisms (SNPsrs1130864, rs1205, rs1800947, and rs2794521) have been associated with variations in CRP levels. ${ }^{19,20}$ Furthermore, both depression and CRP phenotypes exhibit a genetic tendency of $40 \%$ and twin studies have also indicated that depression and inflammation share a common genetic pathway. ${ }^{21}$

Despite such evidence, few studies have investigated the relationship between CRP gene polymorphisms and depressive symptoms, with two adult studies reporting no relationship between the CRP gene and depressive or affective symptoms. ${ }^{22,23}$ However, another study reported the presence of 
such a relationship in older adults, but the effects of somatic diseases, i.e., chronic diseases involving cardiovascular abnormalities and/or inflammation, were not considered. ${ }^{24}$ Moreover, previous phenotypic studies and etiological studies have suggested that the relationship between the CRP gene and depression may differ between men and women in older age cohorts. ${ }^{19,24}$ Despite a dearth of relevant research, some authors have suggested that the CRP gene modifies the relationship between depressive symptoms and CRP levels. ${ }^{23}$

Therefore, in the present study, we aimed to more accurately describe the associations between the CRP gene and depressive symptoms/antidepressant efficacy in patients with depression.

\section{METHODS}

\section{Participants}

We recruited 440 patients (mean age: $34.57 \pm 11.97$ years; 190 men, 250 women) with first-episode major depressive disorder from the First Hospital of Shanxi Medical University from October 2015 to October 2017. All patients were interviewed by at least two experienced psychiatrists and diagnosed via consensus in accordance with the criteria outlined in the Diagnostic and Statistical Manual of Mental Disorders, Fifth Edition (DSM-5). ${ }^{25}$ Demographic information, hospitalization history and medication use were carefully documented, and patients with other mental disorders, hereditary diseases, severe somatic diseases, or bipolar disorder were excluded. All patients were of Han Chinese descent and provided written informed consent prior to participation in the study, which was approved by the Institutional Review Board of the First Hospital of Shanxi Medical University (20091217). The 17-item Hamilton Rating Scale for Depression (HAMD17) and its four-factor at baseline were used to determine clinical characteristics. The lowest baseline HAMD17 score among all participants was 17.

\section{Evaluation of antidepressant use and efficacy}

A total of 250 patients underwent follow up for 6 weeks. All patients were treated solely with selective serotonin reuptake inhibitors (SSRIs), i.e., escitalopram, paroxetine, sertraline, and fluoxetine at initial doses of $10 \mathrm{mg} / \mathrm{d}, 20 \mathrm{mg} / \mathrm{d}, 50$ $\mathrm{mg} / \mathrm{d}$, and $20 \mathrm{mg} / \mathrm{d}$, respectively. All patients reached the therapeutic dose within 2 weeks of treatment initiation, with a gradual increase of the dose within those 2 weeks. Patients who presented with sleep disorders were prescribed, small doses of benzodiazepines as appropriate (intermittent use, no more than 10 days), and the dosages were adjusted based on clinical symptoms. A total of 223 patients completed 6 weeks of treatment. These patients were divided into a remission group (6-week HAMD17 $\leq 7)$ and a non-remission group (6- week HAMD17 $>7$ ), into an effective group (reduction rate $\geq 50 \%$ ) and an ineffective group (reduction rate $<50 \%$ ).

\section{Genotyping}

Haploview software was used to screen genetic loci associated with CRP levels. SNPs rs1130864, rs1205, rs1800947, and rs2794521 were tested for association with variations in CRP concentration. SNP rs2794521 occurred in the promoter region, SNP rs 1800947 occurred in the exon 2 region, and SNPs rs1130864 and rs1205 occurred in the 3'untranslated region. DNA was extracted from whole-blood samples obtained from the cubital vein. The genotypes of the four loci were identified via polymerase chain reaction (PCR) and sequencing techniques. The primers were designed using Primer 5.0 software (PREMIER Biosoft Inc., Palo Alto, CA, USA). Primer homology was compared by entering multiple pairs of primers into the BLAST database of the National Library of the United States. The primers with the least homology and suitable Tm values were selected as PCR reaction primers. For genotyping the CRP gene rs1130864, forward primer 5'ACG TTG GAT GAT CTC CAA GAT CTG TCC AAC-3' and reverse primer 5'ACG TTG GAT GTG GGA GCT CGT TAA CTA TGC3'were used. For rs1205, forward primer 5'ACG TTG GAT GGT TTG TCA ATC CCT TGG CTC-3' and reverse primer 5'ACG TTG GAT GCA GTA GCC ATC TTG TTT GCC-3' were used. For rs1800947, forward primer 5'ACG TTG GAT GGA AAT GTG AAC ATG TGG GAC-3' and reverse primer 5'ACG TTG GAT GCC AGT TCA GGA CAT TAG GAC-3' were used. Finally, for rs2794521, forward primer 5'ACG TTG GAT GCT GAG AAA ATG TGT CCA TGC-3' and reverse primer 5'ACG TTG GAT GCC CTT CCT GTG TCC AAG TAT-3' were used. We utilized a $25-\mu \mathrm{L}$ PCR reaction system containing the following: $60 \mathrm{ng}$ genomic DNA, $200 \mu \mathrm{mol}$ dNTPs, $2.5 \mu \mathrm{L}$ of $10 \times \mathrm{PCR}$ buffer, 5 pmol of each primer, and 1 unit of TaqDNA polymerase. PCR was performed under the following conditions: pre-denaturation at $95^{\circ} \mathrm{C}$ for $5 \mathrm{~min}$, followed by $35 \mathrm{cycles}$ at $94^{\circ} \mathrm{C}$ for $30 \mathrm{~s}, 63^{\circ} \mathrm{C}$ annealing for $30 \mathrm{~s}$, $72^{\circ} \mathrm{C}$ for $30 \mathrm{~s}$, and a final elongation at $72^{\circ} \mathrm{C}$ for $10 \mathrm{~min}$ (supplied by BGI-Huada Genomics Institute, Shenzhen).

\section{Statistical analysis}

The goodness-of-fit chi-square test was used to examine Hardy-Weinberg equilibrium for the genotypic distribution of SNPs. UNPHASED software was used to analyze linkage disequilibrium and quantitative traits. Curative effects were analyzed using SPSS ver. 23.0 (IBM Corp., Armonk, NY, USA). Genotype frequencies $<0.01$ were excluded. The level of statistical significance was set at $\mathrm{p}<0.05$ (two-tailed). 


\section{RESULTS}

\section{General information}

Four CRP SNPS exhibited Hardy-Weinberg equilibrium (Table 1). There were no sex-based differences in the distribution of alleles or genotypes at any loci. Linkage disequilibrium (LD) $\mathrm{r} 2$ values were as follows: 0.086 (rs1130864-rs1205, $\mathrm{D}^{\prime}=$ -0.822), 0.000 (rs1130864-rs1800947, D’=-0.332), 0.008

Table 1. C-reactive protein single-nucleotide polymorphisms (SNPs) and Hardy-Weinberg equilibrium

\begin{tabular}{lcccc}
\hline \multirow{2}{*}{ dsSNP } & \multirow{2}{*}{$\begin{array}{c}\text { Minor/ } \\
\text { major allele }\end{array}$} & \multicolumn{3}{c}{ H-W equilibrium $(\mathrm{p})$} \\
\cline { 3 - 5 } & $\mathrm{A} / \mathrm{G}$ & 0.328 & 0.724 & 0.109 \\
rs1130864 & $\mathrm{C} / \mathrm{T}$ & 0.985 & 0.952 & 0.945 \\
rs1205 & $\mathrm{G} / \mathrm{C}$ & 0.565 & 0.285 & 0.625 \\
rs1800947 & $\mathrm{C} / \mathrm{T}$ & 0.311 & 0.471 & 0.426 \\
rs2794521 & & & &
\end{tabular}

(rs113086-rs2794521, D'=0.669), 0.030 (rs1205-rs1800947, $\left.\mathrm{D}^{\prime}=-1\right), 0.212\left(\mathrm{rs} 1205-\mathrm{rs} 2794521, \mathrm{D}^{\prime}=-0.980\right)$, and 0.007 (rs1800947-rs2794521, D’=-1).

\section{CRP gene polymorphisms and depressive symptoms}

Quantitative trait analysis revealed no direct association between CRP SNPs and depressive symptoms when all patients were included in the analysis. In this study, association analysis based on gender stratification was carried out. In male patients, we observed significant associations between depressive symptoms and two of the four SNPs (Table 2). Among female patients, only rs2794521 was significantly associated with depressive symptoms (Table 3 ). Average insomnia symptoms scores were lower in male patients with the rs1800947 G allele than in those with the C allele (Table 4). Less common recessive genotypes were associated with lower scores on items related to anxiety /physical symptoms and total HAMD17 score in male patients with rs2794521 (Table 5).

Table 2. HAMD17 total and clusters scores and the C-reactive protein gene alleles and genotypes of male patients with major depression $(\mathrm{N}=190)$

\begin{tabular}{|c|c|c|c|c|c|c|c|c|}
\hline \multirow{3}{*}{ Marker } & \multicolumn{8}{|c|}{$\mathrm{p}$} \\
\hline & \multicolumn{2}{|c|}{ rs1130864 } & \multicolumn{2}{|c|}{ rs1205 } & \multicolumn{2}{|c|}{ rs1800947 } & \multicolumn{2}{|c|}{ rs2794521 } \\
\hline & Allele & Genotype & Allele & Genotype & Allele & Genotype & Allele & Genotype \\
\hline Anxiety/physical symptoms & 0.498 & 0.800 & 0.721 & 0.896 & 0.434 & 0.283 & 0.345 & $0.010^{*}$ \\
\hline Cognitive disorder & 0.174 & 0.399 & 0.950 & 0.819 & 0.390 & 0.858 & 0.116 & 0.267 \\
\hline Retardation symptoms & 0.106 & 0.230 & 0.651 & 0.320 & 0.613 & 0.627 & 0.133 & 0.125 \\
\hline Insomnia symptoms & 0.631 & 0.514 & 0.658 & 0.352 & $0.036^{*}$ & 0.224 & 0.351 & 0.550 \\
\hline 1 Depressed mood & 0.361 & 0.212 & 0.980 & 0.385 & 0.543 & 0.747 & 0.570 & 0.721 \\
\hline 2 Feelings of guilt & 0.564 & 0.609 & 0.989 & 0.848 & 0.432 & 0.496 & 0.206 & 0.426 \\
\hline 3 Suicide & 0.419 & 0.630 & 0.322 & 0.065 & 0.722 & 0.836 & 0.189 & 0.400 \\
\hline 4 Insomnia early & 0.499 & 0.396 & 0.296 & 0.534 & 0.916 & 0.914 & 0.513 & 0.458 \\
\hline 5 Insomnia middle & 0.393 & 0.652 & 0.476 & 0.227 & 0.896 & 0.894 & 0.581 & 0.300 \\
\hline 6 Insomnia late & 0.154 & 0.354 & 0.685 & 0.908 & 0.902 & 0.900 & 0.756 & 0.373 \\
\hline 7 Work and activities & 0.718 & 0.916 & 0.363 & 0.626 & 0.795 & 0.935 & 0.490 & 0.735 \\
\hline 8 Retardation: psychomotor & 0.396 & 0.625 & 0.519 & 0.791 & 0.991 & 0.751 & 0.112 & 0.216 \\
\hline 9 Agitation & 0.209 & 0.062 & 0.344 & 0.194 & 0.599 & 0.939 & 0.641 & 0.799 \\
\hline 10 Anxiety (psychological) & 0.788 & 0.938 & 0.469 & 0.757 & 0.974 & 0.945 & 0.637 & $0.046^{*}$ \\
\hline 11 Anxiety somatic & 0.247 & 0.492 & 0.771 & 0.718 & 0.281 & 0.168 & 0.326 & 0.174 \\
\hline 12 Somatic symptoms (gastrointestinal) & 0.506 & 0.312 & 0.942 & 0.953 & 0.565 & 0.290 & 0.900 & 0.385 \\
\hline 13 Somatic symptoms general & 0.890 & 0.129 & 0.104 & 0.189 & 0.165 & 0.334 & 0.291 & 0.145 \\
\hline 14 Genital symptom & 0.394 & 0.381 & 0.417 & 0.379 & 0.532 & 0.527 & 0.140 & 0.110 \\
\hline 15 Hypochondriasis & 0.802 & 0.929 & 0.457 & 0.617 & 0.801 & 0.862 & 0.058 & 0.073 \\
\hline 16 Loss of weight & 0.321 & 0.302 & 0.917 & 0.147 & 0.651 & 0.406 & 0.675 & 0.642 \\
\hline 17 Insight & 0.126 & 0.119 & 0.175 & 0.228 & 0.313 & 0.309 & 0.923 & 0.917 \\
\hline HAMD17 total score & 0.403 & 0.571 & 0.940 & 0.192 & 0.055 & 0.173 & 0.179 & $0.001^{*}$ \\
\hline
\end{tabular}

${ }^{*} \mathrm{p}<0.05 .1-17$ represents HAMD17. Clusters represent HAMD17 and its four-factor. HAMD17: Hamilton Rating Scale for Depression 17 
$X$ Li et al.

Table 3. HAMD17 total and clusters scores and the C-reactive protein gene alleles and genotypes of female patients with major depression $(\mathrm{N}=250)$

\begin{tabular}{|c|c|c|c|c|c|c|c|c|}
\hline \multirow{3}{*}{ Marker } & \multicolumn{8}{|c|}{$\mathrm{p}$} \\
\hline & \multicolumn{2}{|c|}{ rs1130864 } & \multicolumn{2}{|c|}{ rs1205 } & \multicolumn{2}{|c|}{ rs1800947 } & \multicolumn{2}{|c|}{ rs2794521 } \\
\hline & Allele & Genotype & Allele & Genotype & Allele & Genotype & Allele & Genotype \\
\hline Anxiety/physical symptoms & 0.318 & 0.292 & 0.840 & 0.973 & 0.803 & 0.800 & 0.820 & 0.791 \\
\hline Cognitive disorder & 0.800 & 0.789 & 0.300 & 0.235 & 0.914 & 0.912 & 0.486 & 0.768 \\
\hline Retardation symptoms & 0.945 & 0.942 & 0.853 & 0.594 & 0.238 & 0.231 & 0.729 & 0.909 \\
\hline Insomnia symptoms & 0.269 & 0.244 & 0.333 & 0.523 & 0.607 & 0.601 & 0.661 & 0.904 \\
\hline 1 Depressed mood & 0.541 & 0.518 & 0.706 & 0.660 & 0.187 & 0.180 & 0.789 & 0.886 \\
\hline 2 Feelings of guilt & 0.694 & 0.678 & 0.712 & 0.546 & 0.933 & 0.932 & 0.848 & 0.879 \\
\hline 3 Suicide & 0.443 & 0.418 & 0.189 & 0.384 & 0.522 & 0.515 & 0.677 & 0.912 \\
\hline 4 Insomnia early & 0.475 & 0.450 & 0.902 & 0.423 & 0.169 & 0.164 & 0.894 & 0.988 \\
\hline 5 Insomnia middle & 0.498 & 0.471 & 0.888 & 0.817 & 0.988 & 0.988 & 0.765 & $0.034^{*}$ \\
\hline 6 Insomnia late & 0.218 & 0.195 & 0.324 & 0.498 & 0.563 & 0.558 & 0.745 & 0.864 \\
\hline 7 Work and activities & 0.335 & 0.310 & 0.316 & 0.481 & 0.256 & 0.248 & 0.105 & 0.169 \\
\hline 8 Retardation: psychomotor & 0.954 & 0.951 & 0.172 & 0.375 & 0.442 & 0.434 & 0.194 & 0.404 \\
\hline 9 Agitation & 0.932 & 0.929 & 0.770 & 0.512 & 0.705 & 0.700 & 0.462 & 0.723 \\
\hline 10 Anxiety (psychological) & 0.571 & 0.550 & 0.519 & 0.779 & 0.843 & 0.841 & 0.867 & 0.715 \\
\hline 11 Anxiety somatic & 0.075 & 0.060 & 0.823 & 0.956 & 0.394 & 0.387 & 0.266 & 0.380 \\
\hline 12 Somatic symptoms (gastrointestinal) & 0.883 & 0.876 & 0.818 & 0.507 & 0.515 & 0.508 & 0.638 & 0.206 \\
\hline 13 Somatic symptoms general & 0.695 & 0.678 & 0.622 & 0.266 & 0.248 & 0.240 & 0.667 & 0.909 \\
\hline 14 Genital symptom & 0.743 & 0.730 & 0.872 & 0.859 & 0.802 & 0.799 & 0.530 & 0.707 \\
\hline 15 Hypochondriasis & 0.901 & 0.896 & 0.376 & 0.584 & 0.930 & 0.929 & 0.814 & 0.907 \\
\hline 16 Loss of weight & 0.616 & 0.597 & 0.180 & 0.302 & 0.559 & 0.551 & 0.215 & 0.275 \\
\hline 17 Insight & 0.343 & 0.314 & 0.795 & 0.779 & 0.825 & 0.823 & 0.224 & 0.240 \\
\hline HAMD17 total score & 0.212 & 0.187 & 0.960 & 0.966 & 0.734 & 0.730 & 0.637 & 0.851 \\
\hline
\end{tabular}

${ }^{*} \mathrm{p}<0.05 .1$-17 represents HAMD17. Clusters represent HAMD17 and its four-factor. HAMD17: Hamilton Rating Scale for Depression 17

Table 4. Hamilton Rating Scale for Depression 17 cluster scores and the C-reactive protein rs1800947 gene alleles in male patients with major depression

\begin{tabular}{|c|c|c|c|c|c|}
\hline \multirow{3}{*}{ Marker } & \multicolumn{2}{|c|}{ Allele } & \multirow{3}{*}{$\chi^{2}$} & \multirow{3}{*}{ p-value } & \multirow{3}{*}{ Adjusted p-value } \\
\hline & \multicolumn{2}{|c|}{ Mean score (standard deviation) } & & & \\
\hline & $\mathrm{C}(\mathrm{N}=363)$ & $\mathrm{G}(\mathrm{N}=17)$ & & & \\
\hline Insomnia symptoms & $3.68 \pm 1.74$ & $2.76 \pm 1.52$ & 4.384 & 0.036 & 0.048 \\
\hline
\end{tabular}

*the adjusted p-value after 10,000 permutation tests. $\mathrm{n}$ represents the number of patients carrying $\mathrm{C}$ and $\mathrm{G}$ alleles

Dominant genotypes were associated with higher insomnia middle scores among female patients in rs2794521 (Table 5). These findings were not observed in the allelic study for rs2794521 when men and women were analyzed separately. The results remained unchanged after 10,000 permutations.

\section{CRP gene polymorphisms and antidepressants efficacy}

A rs2794521-sex interaction was found in the effective and ineffective model. In further studies, among female patients, treatment efficacy was lower for patients with the rs2794521TT genotype than for patients with other genotypes (Table 6). Meanwhile, rs1130864-rs1205-rs1800947-rs2794521-sex and rs1130864-rs1205-rs1800947-rs2794521 were not related to antidepressants efficacy (Table 7).

\section{CRP gene polymorphisms, depressive symptoms, and antidepressants efficacy}

Among female patients, CRP rs2794521 was associated with both depressive symptoms and antidepressants efficacy. Moreover, in those with the TT genotype, the insomnia middle 
Table 5. Hamilton Rating Scale for Depression 17 (HAMD17) total and clusters scores and the C-reactive protein rs2794521 genotype in patients with major depression

\begin{tabular}{|c|c|c|c|c|c|c|c|}
\hline \multirow{2}{*}{ Sex } & \multirow{2}{*}{ Marker } & \multicolumn{3}{|c|}{ Genotype } & \multirow{2}{*}{$\chi^{2}$} & \multirow{2}{*}{$\mathrm{p}$-value } & \multirow{2}{*}{$\begin{array}{l}\text { Adjusted } \\
\text { p-value* }\end{array}$} \\
\hline & & \multicolumn{3}{|c|}{ Mean score (standard deviation) } & & & \\
\hline \multirow[t]{3}{*}{ Male patients } & & $\mathrm{CC}(\mathrm{N}=2)$ & $\mathrm{CT}(\mathrm{N}=44)$ & $\mathrm{TT}(\mathrm{N}=144)$ & & & \\
\hline & Anxiety/physical symptoms & $2.50 \pm 2.12$ & $7.05 \pm 2.52$ & $7.01 \pm 2.29$ & 9.136 & 0.010 & 0.013 \\
\hline & HAMD total score & 17.00 & $23.18 \pm 3.69$ & $21.60 \pm 4.06$ & 14.170 & 0.001 & 0.002 \\
\hline \multirow[t]{2}{*}{ Female patients } & & $\mathrm{CC}(\mathrm{N}=5)$ & $\mathrm{CT}(\mathrm{N}=72)$ & $\mathrm{TT}(\mathrm{N}=173)$ & & & \\
\hline & Insomnia middle & $1.20 \pm 0.45$ & $1.28 \pm 0.86$ & $1.37 \pm 0.73$ & 6.735 & 0.034 & 0.043 \\
\hline
\end{tabular}

*the adjusted p-value after 10,000 permutation tests. $\mathrm{n}$ represents the number of patients carrying CC, CT, or TT genotypes

Table 6. Antidepressants efficacy and the C-reactive protein genotypes/sex of patients with major depression $(\mathrm{N}=223)$

\begin{tabular}{|c|c|c|c|c|c|c|c|}
\hline \multicolumn{3}{|c|}{ Marker } & \multirow{2}{*}{$\frac{b}{0.131}$} & \multirow{2}{*}{$\begin{array}{c}\mathrm{S}_{\mathrm{b}} \\
0.873\end{array}$} & \multirow{2}{*}{$\begin{array}{c}\text { WaldX }^{2} \\
0.022\end{array}$} & \multirow{2}{*}{$\begin{array}{c}p \\
0.881\end{array}$} & \multirow{2}{*}{$\begin{array}{r}\text { OR } \\
1.140\end{array}$} \\
\hline Effective and ineffective & rs1130864 & SNP-sex & & & & & \\
\hline & & SNP & 0.142 & 1.522 & 0.009 & 0.926 & 1.152 \\
\hline & & Sex & -0.670 & 1.639 & 0.167 & 0.683 & 0.512 \\
\hline & rs1205 & SNP-sex & -0.354 & 0.441 & 0.642 & 0.423 & 0.702 \\
\hline & & SNP & 0.296 & 0.737 & 0.161 & 0.688 & 1.344 \\
\hline & & Sex & -0.020 & 0.612 & 0.001 & 0.974 & 0.980 \\
\hline & rs1800947 & SNP-sex & -0.141 & 1.581 & 0.008 & 0.929 & 0.869 \\
\hline & & SNP & 0.797 & 2.476 & 0.104 & 0.748 & 2.219 \\
\hline & & Sex & -0.419 & 0.326 & 1.647 & 0.199 & 0.658 \\
\hline & rs 2794521 & SNP-sex & -1.623 & 0.754 & 4.639 & $0.031^{*}$ & 0.197 \\
\hline & & SNP & 2.034 & 1.196 & 2.891 & 0.089 & 7.644 \\
\hline & & Sex & 2.398 & 1.358 & 3.120 & 0.077 & 11.002 \\
\hline \multirow[t]{12}{*}{ Remission and non-remission } & rs1130864 & SNP-sex & -0.382 & 0.784 & 0.238 & 0.626 & 0.682 \\
\hline & & SNP & 0.333 & 1.338 & 0.062 & 0.804 & 1.395 \\
\hline & & Sex & 0.901 & 1.481 & 0.370 & 0.543 & 2.462 \\
\hline & rs1205 & SNP-sex & -0.176 & 0.376 & 0.220 & 0.639 & 1.193 \\
\hline & & SNP & -0.087 & 0.616 & 0.020 & 0.887 & 0.916 \\
\hline & & Sex & $<0.01$ & 0.511 & $<0.01$ & 0.999 & 1.000 \\
\hline & rs1800947 & SNP-sex & -1.112 & 1.365 & 0.663 & 0.415 & 0.329 \\
\hline & & SNP & 0.969 & 1.898 & 0.260 & 0.610 & 2.635 \\
\hline & & Sex & 0.236 & 0.283 & 0.699 & 0.403 & 1.267 \\
\hline & rs2794521 & SNP-sex & 0.978 & 0.612 & 2.552 & 0.110 & 2.658 \\
\hline & & SNP & -1.407 & 1.002 & 1.969 & 0.161 & 0.245 \\
\hline & & Sex & -1.474 & 1.087 & 1.840 & 0.175 & 0.229 \\
\hline
\end{tabular}

${ }^{*} \mathrm{p}<0.05$

Table 7. Antidepressants efficacy and the C-reactive protein polyloci genotypes/sex of patients with major depression $(\mathrm{N}=223)$

\begin{tabular}{llccccc}
\hline & \multicolumn{1}{c}{ Marker } & $\mathrm{b}$ & $\mathrm{S}_{\mathrm{b}}$ & $\mathrm{WaldX}^{2}$ & $\mathrm{p}$ & $\mathrm{OR}^{2}$ \\
\hline Effective and ineffective & rs1130864-rs1205-rs1800947-rs2794521-sex & 0.321 & 0.290 & 1.225 & 0.268 & 1.379 \\
& rs1130864-rs1205-rs1800947-rs2794521 & 0.861 & 0.590 & 2.127 & 0.145 & 2.365 \\
Remission and non-remission & rs1130864-rs1205-rs1800947-rs2794521-sex & -0.310 & 0.224 & 1.921 & 0.166 & 0.734 \\
& rs1130864-rs1205-rs1800947-rs2794521 & -0.440 & 0.278 & 2.496 & 0.114 & 0.644 \\
\hline
\end{tabular}


scores were higher, while the antidepressants efficacy was lower.

\section{DISCUSSION}

In the present study, we investigated whether CRP gene polymorphisms were related to depressive symptoms and antidepressants efficacy. However, the relationships between CRP SNPs and depressive symptoms/antidepressants efficacy were not observed uniformly in all patients. Among male patients, rare recessive genotypes or alleles of the CRP gene (rs2794521 CC and rs1800947 G) were associated with significantly lower depressive symptom scores. Among female patients, dominant genotypes were associated with higher mean insomnia scores and lower antidepressants efficacy in those with rs2794521. Since the UNPHASED analysis indicated that rs1205, rs1130864, rs1800947, and rs2794521 were not in the same LD region, haplotype analyses were not performed.

At present, few studies have examined the relationship between CRP SNPs and depressive symptoms, yielding controversial results. In two adult studies, the authors reported no association between the CRP gene and depressive or affective symptoms. ${ }^{22,23}$ Luciano et al. ${ }^{24}$ adjusted for sex and age in two cohorts of older adults, and reported that rs1130864T and rs1205A were associated with anxiety and neuroticism in female patients. Another ${ }^{26}$ group reported an association between rs1130864T and aggressive behavior in women. KittelSchneider et al. ${ }^{27}$ demonstrated that rs 1800947 CG and CC were associated with greater depressive symptoms in patients with chronic heart failure. In accordance with these findings, our results suggest that CRP SNPs exhibit sex-specific associations with depressive symptoms. Positive results were observed among male and female patients, and the main loci were rs1800947 and rs2794521. In contrast to previous results, we observed no associations between depressive symptoms and rs1205 or rs1130864 in female patients. Such discrepancies may be explained by the low number of female patients, age differences in subjects among studies, and differences in the research methods utilized. In our study, rare recessive genotypes or alleles of the CRP gene (rs2794521 CC and rs1800947 G) were associated with significantly lower depressive symptom scores in male patients. However, rs2794521 was associated with a similar result in female patients. No previous study has examined associations for rs2794521, which we found to be significantly associated with depressive symptoms even after 10,000 permutations. Indeed, rs2794521 may have functional significance in patients with depression, given that it is located in the 5 'promoter region, which is known to regulate gene expression.

In our study, dominant genotypes were associated with lower efficacy of antidepressants in female patients with rs2794521, suggesting that different CRP gene loci are associated with different therapeutic mechanisms. Therefore, our findings have implications for the development of new antidepressants and individualized treatment strategies.

Our study provides new evidence that the CRP gene regulates depressive symptoms and antidepressants efficacy. Indeed, our findings indicated that rs2794521 was associated with depressive symptoms and antidepressants efficacy in female patients. In those with the TT genotype, the insomnia middle scores were higher, while treatment efficacy was lower. We speculate that the TT genotype may regulate antidepressants efficacy via depressive symptoms (Insomnia middle) in female patients with depression. While it must be acknowledged that CRP SNPs may have other functions as well, our results indicate that the high depressive symptom scores may explain the lower reduction rates. In one previous study, ${ }^{22}$ clinical symptoms were more closely related to metabolic syndrome in patients with the CC genotype of rs1205 than in those with other genotypes. Furthermore, the association between Center for Epidemiological Studies Depression Scale (CESD) scores and CRP levels has been shown to be stronger in individuals with the A-G-T haplotype (rs1417938-rs1800947-rs1205). ${ }^{23}$ However, as we did not measure plasma CRP concentrations, our results cannot be directly compared with these findings.

Numerous studies have suggested a positive correlation between depression and physical disease, indicating that inflammatory factors, such as CRP, may play an important role in the pathogenesis of depression. Increased plasma CRP concentration in patients with depression induces a persistent increase in cortisol concentration, ${ }^{28-30}$ which further promotes the secretion of inflammatory factors, such as tumor necrosis factor- $\alpha$ (TNF- $\alpha$ ) and interleukin 6 (IL-6), ${ }^{31}$ which damages the function of glucocorticoid receptors and causes hyperactivity of the hypothalamic pituitary adrenal (HPA) axis. ${ }^{32}$ Further, increased cortisol concentration affects the synthesis of 5 hydroxytryptamine (5-HT). ${ }^{33}$ Together, these responses lead to depression. Therefore, in this study, we examined the efficacy of SSRIs-the first-line treatment recommended for depression-as they act to increase 5-HT levels in the brain. Our findings suggest that efficacy of SSRIs can be predicted based on CRP gene variants.

The gender difference might be attributed not only to CRP, but also to hormones, as CRP fluctuates with sex hormones. ${ }^{34-36}$ A previous study found that sex hormones have different effects on HPA axis function. ${ }^{37}$ Gender differences also exist in the function of estrogen receptors and glucocorticoid receptors on HPA axis. ${ }^{38,39}$ The cortisol/CRP ratio regulates depressive symptoms and may also exhibit gender differences. ${ }^{40}$ While we observed sex-specific associations between CRP SNPs and depressive symptoms/ antidepres- 
sants efficacy, further studies are required to determine whether these associations are mediated by the HPA axis.

The present study possesses some notable limitations, including the small number of patients with rare genotypes. By further analyzing allelic rather than genotypic effects, we were unable to reach similar conclusions. Therefore, further studies including larger sample sizes are required to verify our hypothesis. In addition, since we utilized a cross-sectional design, we were unable to exclude patients who may have continued to develop bipolar disorder.

In summary, our findings indicate that the CRP SNPs rs1800947 and rs2794521 may exhibit sex-specific associations with depressive symptoms in patients with depression. Furthermore, rs2794521 may be a predictor of antidepressants efficacy in female patients. This is the first study to focus on the relationship between the CRP gene and the efficacy of antidepressant in a population, and the first study on the relationship between the CRP gene and depressive symptoms in a Han Chinese population. Therefore, our results may aid in the development of novel strategies for preventing and treating depression.

\section{Acknowledgments}

This study was supported by the National Natural Science Youth Fund Project $(81701345,81601192,81601193)$, the National key research and development program of China (2016YFC1307103), National Clinical Research Center on Mental Disorders (2015BAI13B02), National Key Basic Research Program (No.2013CB531305), Application Basic Research Project in Shanxi Province (201801D221418), Shanxi Health and Family Planning Commission Scientific Research Project (201601034), Program for the Outstanding Innovative Teams of Higher Learning Institutions of Shanxi, and Shanxi Province Graduate Student Education Innovation at 2017 (2017BY079). We sincerely thank the patients and their families, as well as the healthy volunteers for their participation, and all the medical staffs involved in the collection of specimens.

\section{Conflicts of Interest}

The authors have no potential conflicts of interest to disclose.

\section{Author Contributions}

Conceptualization: Kerang Zhang, Xinxin Li. Data curation: Xinxin Li, Kerang Zhang. Formal analysis: Xinxin Li, Chunxia Yang. Funding acquisition: Ning Sun, Chunxia Yang, Zhifen Liu, Xinrong Li, Kerang Zhang. Investigation: Zhifen Liu, Xinrong Li. Methodology: Ning Sun, Chunxia Yang, Xinxin Li. Supervision: Kerang Zhang. Writing_original draft: Xinxin Li. Writing_-review \& editing: Ning Sun, Chunxia Yang, Zhifen Liu, Xinrong Li.

\section{ORCID iDs}

$\begin{array}{ll}\text { Kerang Zhang } & \text { https://orcid.org/0000-0002-7397-2738 } \\ \text { Xinxin Li } & \text { https://orcid.org/0000-0002-6296-4409 }\end{array}$

\section{REFERENCES}

1. Sumiyoshi T, Watanabe K, Noto S, Sakamoto S, Moriguchi Y, Okamoto S. Prospective Epidemiological Research on Functioning Outcomes Related to Major Depressive Disorder in Japan (PERFORM-J): protocol for a prospective cohort study. JMIR Res Protoc 2018;7:e161.

2. Kohler CA, Freitas TH, Stubbs B, Maes M, Solmi M, Veronese N, et al.
Peripheral alterations in cytokine and chemokine levels after antidepressant drug treatment for major depressive disorder: systematic review and meta-analysis. Mol Neurobiol 2018;55:4195-4206.

3. Ma L, Demin KA, Kolesnikova TO, Khatsko SL, Zhu X, Yuan X, et al. Animal inflammation-based models of depression and their application to drug discovery. Expert Opin Drug Discov 2017;12:995-1009.

4. Lopresti AL. Cognitive behaviour therapy and inflammation: a systematic review of its relationship and the potential implications for the treatment of depression. Aust N Z J Psychiatry 2017;51:565-582.

5. Horn SR, Long MM, Nelson BW, Allen NB, Fisher PA, Byrne ML. Replication and reproducibility issues in the relationship between Creactive protein and depression: a systematic review and focused metaanalysis. Brain Behav Immun 2018;73:85-114.

6. Felger JC, Haroon E, Patel TA, Goldsmith DR, Wommack EC, Woolwine BJ, et al. What does plasma CRP tell us about peripheral and central inflammation in depression? Mol Psychiatry 2018 [Epub ahead of print].

7. Chang HH, Wang TY, Lee IH, Lee SY, Chen KC, Huang SY, et al. C-reactive protein: a differential biomarker for major depressive disorder and bipolar II disorder. World J Biol Psychiatry 2017;18:63-70.

8. Strawbridge R, Arnone D, Danese A, Papadopoulos A, Herane Vives A, Cleare AJ. Inflammation and clinical response to treatment in, depression: a meta-analysis. Eur Neuropsychopharmacol 2015;25:1532-1543.

9. Haapakoski R, Mathieu J, Ebmeier KP, Alenius H, Kivimaki M. Cumulative meta-analysis of interleukins 6 and 1 beta, tumour necrosis factor alpha and C-reactive protein in patients with, major depressive disorder. Brain Behavior Immun 2015;49:206-215.

10. Tayefi M, Shafiee M, Kazemi-Bajestani SMR, Esmaeili H, Darroudi S, Khakpouri S, et al. Depression and anxiety both associate with serum level of hs-CRP: a gender-stratified analysis in a population-based study. Psychoneuroendocrinology 2017;81:63-69.

11. Xia QR, Liang J, Cao Y, Shan F, Liu Y, Xu YY. Increased plasma nesfatin-1 levels may be associated with corticosterone, IL-6, and CRP levels in patients with major depressive disorder. Clin Chim Acta 2018;480:107-111.

12. Hur NW, Kim HC, Waite L, Youm Y. Is the relationship between depression and $\mathrm{C}$ reactive protein level moderated by social support in elderly?-Korean Social Life, Health, and Aging Project (KSHAP). Psychiatry Investig 2018;15:24-33.

13. Chang HH, Lee IH, Gean PW, Lee SY, Chi MH, Yang YK, et al. Treatment response and cognitive impairment in major depression: association with C-reactive protein. Brain Behav Immun 2012;26:90-95.

14. Krogh J, Benros ME, Jorgensen MB, Vesterager L, Elfving B, Nordentoft $\mathrm{M}$. The association between depressive symptoms, cognitive function, and inflammation in major depression. Brain Behavior Immun 2014;35:70-76.

15. Valkanova V, Ebmeier KP, Allan CL. CRP, IL-6 and depression: a systematic review and meta-analysis of longitudinal studies. J Affect Disord 2013;150:736-744.

16. Uher R, Tansey KE, Dew T, Maier W, Mors O, Hauser J, et al. An inflammatory biomarker as a differential predictor of outcome of depression treatment with escitalopram and nortriptyline. Am J Psychiatry 2014;171:1278-1286.

17. Miller ES, Hoxha D, Pinheiro E, Grobman WA, Wisner KL. The association of serum C-reactive protein with the occurrence and course of postpartum depression. Arch Womens Ment Health 2019;22:129-132.

18. Tayefi M, Tajfard M, Saffar S, Hanachi P, Amirabadizadeh AR, Esmaeily $\mathrm{H}$, et al. hs-CRP is strongly associated with coronary heart disease (CHD): a data mining approach using decision tree algorithm. Comput Methods Programs Biomed 2017;141:105-109.

19. Ancelin ML, Farre A, Carriere I, Ritchie K, Chaudieu I, Ryan J. C-reactive protein gene variants: independent association with late-life depression and circulating protein levels. Transl Psychiatry 2015;5e499.

20. Kettunen T, Eklund C, Kahonen M, Jula A, Paiva H, Lyytikainen LP, et al. Polymorphism in the C-reactive protein (CRP) gene affects CRP levels in plasma and one early marker of atherosclerosis in men: the Health 2000 Survey. Scand J Clin Lab Invest 2011;71:353-361. 
21. Su S, Miller AH, Snieder H, Bremner JD, Ritchie J, Maisano C, et al. Common genetic contributions to depressive symptoms and inflammatory markers in middle-aged men: the Twins Heart Study. Psychosom Med 2009;71:152-158.

22. Gaysina D, Pierce M, Richards M, Hotopf M, Kuh D, Hardy R. Association between adolescent emotional problems and metabolic syndrome: the modifying effect of C-reactive protein gene (CRP) polymorphisms. Brain Behavior Immun 2011;25:750-758.

23. Halder I, Marsland AL, Cheong J, Muldoon MF, Ferrell RE, Manuck SB. Polymorphisms in the CRP gene moderate an association between depressive symptoms and circulating levels of C-reactive protein. Brain Behav Immun 2010;24:160-167.

24. Luciano M, Houlihan LM, Harris SE, Gow AJ, Hayward C, Starr JM, et al. Association of existing and new candidate genes for anxiety, depression and personality traits in older people. Behav Genet 2010;40:518-532.

25. Mittal VA, Walker EF. Diagnostic and statistical manual of mental disorders. Psychiatry Res 2011;189:158-159.

26. Suchankova P, Henningsson S, Baghaei F, Rosmond R, Holm G, Ekman A. Genetic variability within the innate immune system influences personality traits in women. Genes Brain Behav 2009;8:212-217.

27. Kittel-Schneider S, Kaspar M, Berliner D, Weber H, Deckert J, Ertl G, et al. CRP genetic variants are associated with mortality and depressive symptoms in chronic heart failure patients. Brain Behav Immun 2018; 71:133-141.

28. Cubala WJ, Landowski J. C-reactive protein and cortisol in drug-naive patients with short-illness-duration first episode major depressive disorder: possible role of cortisol immunomodulatory action at early stage of the disease. J Affect Disord 2014;152-154:534-537.

29. Cubala WJ, Landowski J, Dziadziuszko M, Chrzanowska A, Wielgomas B. Magnesium, C-reactive protein, and cortisol in drug-naive patients with short illness-duration, first episode major depressive disorder: possible immunomodulatory role for magnesium. Magnes Res 2016;29:169-174.
30. Verduijn J, Milaneschi Y, Schoevers RA, van Hemert AM, Beekman AT, Penninx BW. Pathophysiology of major depressive disorder: mechanisms involved in etiology are not associated with clinical progression. Transl Psychiatry 2015;5:e649.

31. Pavon L, Sandovallopez G, Eugeniahernandez M, Loria F, Estrada I, Perez M, et al. Th2 cytokine response in Major Depressive Disorder patients before treatment. J Neuroimmunol 2006;172:156-165.

32. McQuade R, Young AH. Future therapeutic targets in mood disorders: the glucocorticoid receptor. Br J Psychiatry 2000;177:390-395.

33. Cowen PJ. Cortisol, serotonin and depression: all stressed out? Br J Psychiatry 2002;180:99-100.

34. Rossi R, Bursi F, Veronesi B, Cagnacci A, Modena MG. Effects of progestins on estrogen-induced increase in C-reactive protein in postmenopausal women. Maturitas 2004;49:315-320.

35. Ryan J, Carriere I, Scali J, Ritchie K, Ancelin ML. Lifetime hormonal factors may predict late-life depression in women. Int Psychogeriatr 2008;20:1203-1218.

36. Skouby SO, Gram J, Andersen LF, Sidelmann J, Petersen KR, Jespersen J. Hormone replacement therapy: estrogen and progestin effects on plasma C-reactive protein concentrations. Am J Obstet Gynecol 2002; 186:969-977.

37. Chrousos GP. Stress and sex versus immunity and inflammation. Sci Signal 2010;3:pe36.

38. Kumsta R, Entringer S, Koper JW, van Rossum EFC, Hellhammer DH, Wüst S. Sex specific associations between common glucocorticoid receptor gene variants and hypothalamus-pituitary-adrenal axis responses to psychosocial stress. Biol Psychiatry 2007;62:863-869.

39. Handa RJ, Weiser MJ. Gonadal steroid hormones and the hypothalamo-pituitary-adrenal axis. Front Neuroendocrinol 2014;35:197-220.

40. Suarez EC, Sundy JS, Erkanli A. Depressogenic vulnerability and gender-specific patterns of neuro-immune dysregulation: what the ratio of cortisol to C-reactive protein can tell us about loss of normal regulatory control. Brain Behav Immun 2015;44:137-147. 